\title{
THE TRANSITION OF THE QUALITY MANAGEMENT SYSTEMS TO THE NEW REQUIREMENTS REGARDING THE APPROACH BASED ON THE RISK ASSESSMENT IN THE ORGANIZATION'S PROCESSES
}

\author{
Ana Anghel, lonel Virgil Criste
}

National Research and Development Institute for Industrial Ecology, Bucharest, Drumul Podu Dambovitei, no. 71-73, sector 6, postal cod 060652, e-mail: ecoind@incdecoind.ro,Romania

\begin{abstract}
On the basis of implementing a quality management system is ISO 9001 - Quality Management Systems. Requirements. This standard is one of the most used worldwide ISO standards and is revised periodically. The current revision process began in 2011, is carried out to ensure the relevance and update with the new global economic issues and will end in late of September, when it will also be published.

This revision of ISO 9001 proposes a number of changes of which the most important is the risk-based approach in developing quality management systems. At present, approach based on processes is considered insufficient because it does not consider the events that may affect the achievement of objectives and activities.

These events constitute risks with potential impacts on business results and efficiency of resource use. Thus, these risks should be identified and must be established and undertaken those actions that reduce and maintain the risks within acceptable limits.

Taking into consideration these issues, INCD ECOIND has proposed the development of a methodology of transition the current management systems based on processes to the management systems based on risks' consideration.

The methodology will include:

- Establishing the transition Strategy of existing QMS to the requirements of ISO 9001-201;

- Awareness managers and all staff on the requirements of the new standard ISO 9001-2015;

- Integrating risk management process at SMC level;

- Reviewing the system documents according to the requirements of standard ISO 9001-2015;

- Evaluating and improving QMS.
\end{abstract}

The proposed methodology will be useful for organizations that have already implemented a quality management system, as well as for organizations that want to implement this system.

Keywords: methodology, implementation, risk, quality management system, evaluation, audit.

\section{Introduction}

One of the instruments used by top management of organizations to continuously improve their performance is the Quality Management System implemented according to requirements of standard ISO 9001 - Quality Management Systems and developed by the approach based on processes. Through the Quality Management System it is ensure control of all processes from organization and more responsible staff.

One of the key changes made in the last revision of ISO 9001, namely one from 2015 , is to establish a systematic approach of risk, to treat the risk as one component of quality management system. 
At the moment, there are already few models for implementation of risk management within the management systems, namely:

- in the environmental management, to identification of environmental aspects and their evaluation through impacts associated. In this case, environmental issues are dangers and environmental impacts are risks associated.

- in the management of occupational health and safety / health and safety management, which uses three key risk management processes, namely:

* the process of identifying hazards - i.e. factors / causes of risk-source or situation with a potential for injury, sickness, damage property / job environment or combinations thereof;

- the process of determination the risk associated with each danger, assessment of risk level on job and establishing if it is tolerable or not;

* the process of keeping risks under control:

- In the management of program for audits described in ISO 19011 [2]

- In the internal control management system in public entities in accordance with the provisions of Order SGG 400/2015 [4].

Therefore, organizations that have implemented these management systems analyze, at least once a year, risks related to its activities, develop appropriate plans, in order to minimize possible consequences of such risks and establish employees responsible in application of those plans.

This topic was touched even in previous editions of standard ISO 9001, where there was a single clause that addresses the risk, namely one regarding the preventive actions.

\section{Materials end Methods}

In this latest edition of standard 9001, the risk is introduced explicitly, taking into account and included along standard.

Thus, the standard paragraphs in which the risk is tackled, are:

Introduction - where the risk is defined as the effect of uncertainty on the desired result and explains why it was approached the risk-based thinking;

Article 4 - "organization is required to determine its risks that could affect its ability to achieve the objectives";

Article 5 - in which "top management must ensure that the risks and opportunities that may affect the conformity of products and services, as well as the ability to enhance customer satisfaction are determined and addressed";

Article 6. Planning - where organization should take measures to address the risks and opportunities;

Article 8. Operation - in which explicitly required to have processes that identify risk activities / its operations;

Article 9 Performance evaluation - the organization is required to monitor, measure, analyze and assess risks and opportunities;

Article 10 Improvement - it is specified that is necessary for the organization to improve its work responding to changes in risk.

In the context of ISO 9001, the concept of "risk" relates to the uncertainty in achieving the key objectives of the management system, namely:

- Supplying of confidence in ability of the organization to consistently realize goods and services, in accordance with customer requirements;

- Increase customer satisfaction. 
The term: "risk-based thinking" was coined to help the concept of risk to penetrate in the entire QMS and the risk to be also incorporated into the process approach model.

Defining the concept of "risk-based thinking" - means that the organization understand its context and determine the risks as a basis for planning and implementing quality management system processes.

The new edition of ISO 9001 no longer refers to: documents, quality manual, documented procedures and records, they have been replaced by the notion of 'documented information'.

The definition of "documented information" - according to ISO 9000 means information (significant) that must be controlled and maintained by an organization and its environment support.

Hence the term "documented information" is used for all requirements documents.

The consideration of risk across the organization, likelihood of achieving set goals is improved outputs are consistent and customers can rest assured that they will receive the product or service expected.

Therefore, the based on risk thinking:

- builds a strong base of knowledge;

- establishes a proactive culture of improvement;

- ensures consistent quality of goods and services;

- improves reliability and customer satisfaction.

\section{Results}

Taking into consideration these issues, INCD ECOIND has proposed the development of a methodology for transition of the current quality management system based on processes, by considering the risks and other requirements of the new edition of ISO 9001.

The proposed methodology includes:

1. Establish a transition strategy of QMS existent to the requirements of ISO 9001-2015 [1];

2. Awareness of managers and entire staff on the requirements of the new standard ISO 9001-2015;

3. Integrating risk management process at the QMS level;

4. Review the system documents according to the requirements of ISO 9001-2015;

5. Evaluation and improving QMS

\section{Establishing a transition strategy of QMS existent to the requirements of ISO 9001-2015}

Taking into consideration that INCD ECOIND has already implemented a quality management system, the strategy means the following measures:

- Appointment of a working team to implement the requirements of revised reference standard;

- Analysis of standard requirements;

- Identifying practical and documentation activities that must be addressed to meet the requirements of the new standard;

- Developing an implementation plan; 
- Providing appropriate training and awareness to all parties that have an impact on the organization effectiveness;

- Reviewing documentation of existing quality management system (QMS) to meet the requirements of the new standard;

- Checking effectiveness.

The working team established will include head of the Management Quality Environment Compartment and responsible for the quality of the key departments of the institute.

Analysis standard means: analysis of the standard requirements, of Annexes, as well as of other documents concerning the revision of the standard.

To get the maximum benefits associated with changes, that may occur as a result of applying the requirements of the new edition of ISO 9001, the team must consider all changes that might affect its processes and to plan them.

In developing the implementation plan, there are considered: the potential consequences of changes, providing resources, allocation or reallocation of responsibility and authority, QMS integration.

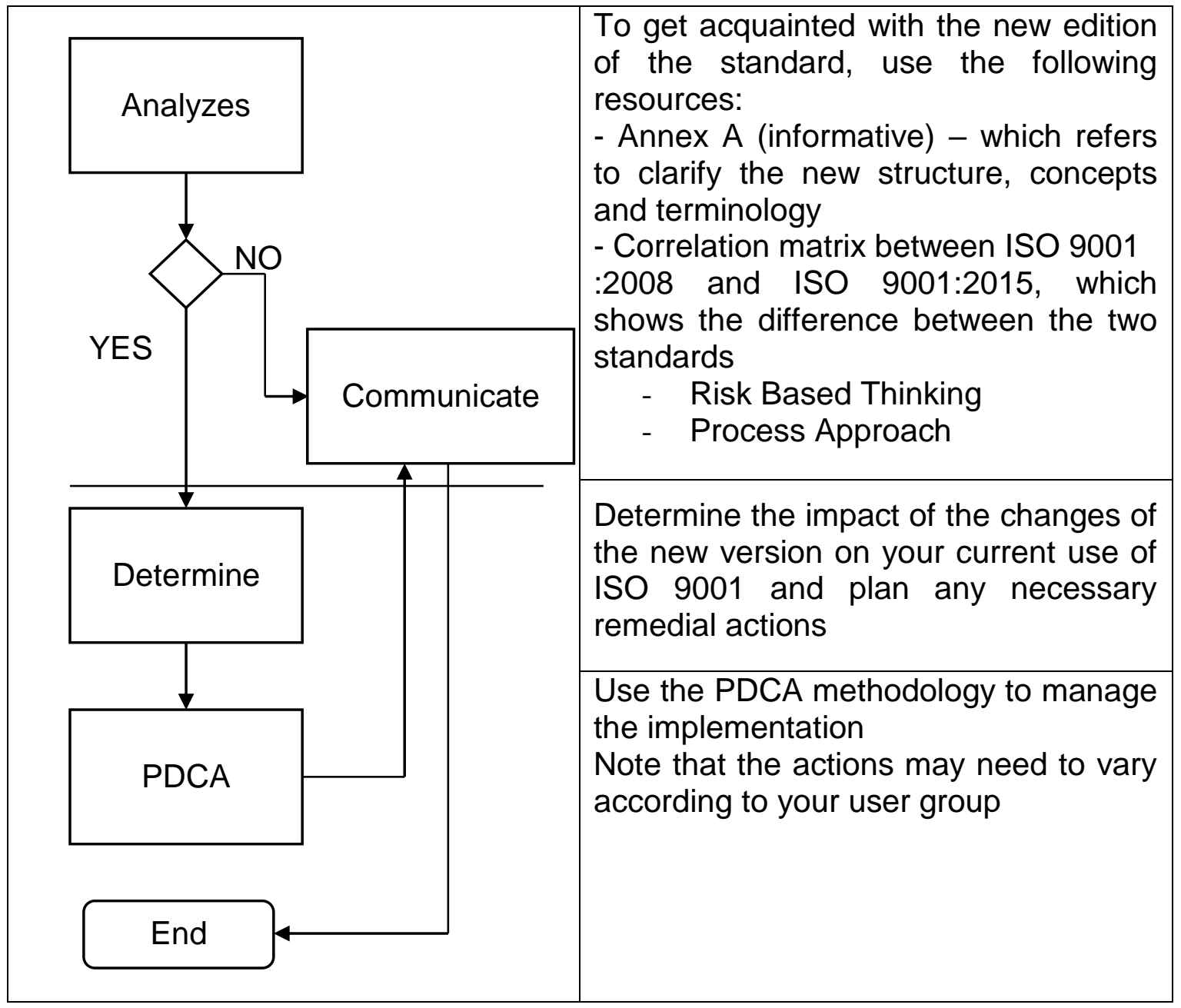

Fig.1 - Table of QMS strategy transition to the new requirements of ISO-9001: 2015 


\section{Awareness of managers and entire staff on the requirements of standard ISO 9001-2015}

An important role in this transition has the training of managers and staff with new or revised requirements of standard ISO 9001: 2015.

The topics proposed include:

- The reasons that led to the revision of the standard;

- Defining and explaining new terms;

- Presentation of the main changes;

- Changes benefits;

- Potential beneficiaries of the changes;

- Presentation of new or modified items;

- Risk approach in ISO 9001: 2015;

- Risk management;

- $\quad$ Limit the transition period for certification.

\section{Integrating risk management process at QMS level}

Risk management process includes the following activities:

- it identifies risks and opportunities in the organization. This identification is based on the context in which the organization operates. Although ISO 9001: 2015 does not require a formal risk assessment or a specific document, information must be stored and available. For a more formal approach to risk, ISO 31000 can be used (Risk management - Principles and guidelines) [3].

- it examines, evaluates and ranks the risks and opportunities of the organization, answering to the questions:

- How to evaluate?

- What is acceptable?

- What is unacceptable?

- In that opportunities should act?

In INCD ECOIND is implemented the internal control management system based on management of risk to achieve business objectives. According to the procedure PL-23 Risk management, are identified and assessed risks, depending on the context in which the institution is operating, by a nominated team, which includes heads of departments and the responsible with the risks. Each QMS process is analyzed and the activities generating risks are identified.

The evaluation method used in INCD ECOIND is a subjective method that is based on the perception of the risk assessor. Risk assessment involves assessing the likelihood of the risk materializing $(P)$ and of impact (consequences) (I) of the objectives when they materialize. The combination of the estimated probabilities and estimated impact represents the risk exposure $(E): E=P x I$.

For both probability and impact are used assessment scales on 5 levels. 
Attitude towards risk is determined given the "appetite (tolerance) for risk": if the threat relates to the level of exposure that is considered tolerable and justifiable as costs when the opportunity refers to the level of acceptable risk to get advantages of the opportunity

- it draws up an action plan to address the risks and opportunities, thus specifying the means by which to avoid, eliminate or reduce risk and how to achieve opportunities.

- it implements the plan or are taken appropriate measures on the elimination, reduction and avoidance of risk, respectively the achievement of the opportunities.

- it verifies the actions effectiveness - respectively it verifies if the mechanism works.

- it learns from gained experience - thus achieving continuous improvement.

Through the inclusion of risk, an organization becomes manly proactive, not reactive, which has the effect of preventing or reducing the undesirable impacts and promoting continuous improvement.

\section{Review documents as required by ISO 9001-2015 system}

After analyzing the requirements of standard and comparing with elaborated system documents, it is established a program for review of documentation and, if necessary, for elaboration of new documents.

The organization shall maintain and keep documented information:

- to support its operation processes and

- to give confidence that its processes are performed as planned

The documented information refers to:

a) documented information relating to the operation of the management system (policy, goals, a.s.o.)

b) examples of documents that can add value to QMS: flowcharts, diagrams of process flow and / or proces descriptions, procedures, working instructions, specifications, production schedules, documents containing internal communications, forms, a.s.o.)

c) documented information required to be retained in order to provide evidence of the results obtained (records), e.g:

- proof of competence of the person (s) under the supervision of the organization that affect efficiency and performance of QMS (clause 7.2);

- records design and development results (clause 8.3.5);

- records of evaluation, selection, monitoring performance and re-evaluation of external suppliers and any actions resulting from these activities (clause 8.4.1);

- QMS performance and efficiency evaluation results (clause 9.1.1);

- proof of implementation of the audit program and proof of the audit results (clause 9.2.2); 
- proof of the results for management analyses (clause 9.3.3);

- proof of the nonconformities nature and any subsequent actions taken (clause 10.2.2);

- results of any corrective action (clause 10.2.2).

It can develop other records to demonstrate compliance of its processes, products and services, as well as of its quality management system.

It can perform also some simplifications and / or enhancements of existing documented information, in order to simplify QMS.

After validation of the system documents reviewed will be hold a training session to all staff on:

- the content and manner of implementing the documented information revised,

- the manner of generate and maintain the records resulting from the use of this documented information in the current activity.

\section{Evaluating and improving QMS}

QMS assessment will be made after the practical application of documented information by conducting an internal audit and the results will be analyzed in a management meeting when suggestions for improvement will be made.

\section{Conclusion}

The proposed methodology is useful for organizations that have already implemented a quality management system. Through applying it, the organization will be ready to a new recertification in accordance with the latest edition of standard ISO 9001: 2015.

\section{References}

[1] ISO 9001(2015), Quality management systems.Requirements, International Standard Organisation

[2] ISO 19011(2011) Guidelines for auditing management systems, International Standard Organisation

[3] ISO 31000(2009) Risk Management - Principles and guidelines, International Standard Organisation

[4] Order no. 400 (2015) for approving Code of internal control / management of public entities, Secretariat General of Government, http://www.sgg.ro/ 